\title{
The Internet of Things (IoT) and Social Interaction: Influence of Source Attribution and Human Specialization
}

\author{
Siddhartha Vadlamudi ${ }^{1 *}$, Donyea Lamont Hargrove ${ }^{2}$ \\ ${ }^{1}$ Software Engineer II, Xandr, AT\&T Services Inc., New York, USA \\ ${ }^{2}$ Retention and Withdrawal Officer, Department of University Student Success, Jackson State University, \\ 1400 JR Lynch st Jackson Ms, USA \\ *Corresponding Contact: \\ Email: vadlamudisiddhartha@gmail.com
}

\begin{abstract}
The evolvement of IT has open new doors in connecting many devices to the worldwide web that successively produce data around the physical setting using the IoT. However, the system of message turns out to be slightly intricate in human specialization-internet of things communication for the reason that the IoT is a system including diverse objects transferring data This study examines the hypothetical pathway by which the changes in source attribution that is multiple against single and specialization that is multi-functionality against single functionality of IoT devices affect the quality of human- internet of things interaction. The result from the study obtained from 80 participants that took part in the experiment shows that multiple source attribution improves the condition of information basically for the low-involvement people supports further probes the multiple source effects. However, this study recommends improvement of attribution source and human specialization-IoT.
\end{abstract}

Key words:

IoT, Source Attribution, Specialization Source, Human-IoT interaction

$4 / 20 / 2021$

Source of Support: None, No Conflict of Interest: Declared

This article is licensed under a Creative Commons Attribution-NonCommercial 4.0 International License.

Attribution-NonCommercial (CC BY-NC) license lets others remix, tweak, and build upon work non-commercially, and although the new works must also acknowledge $\&$ be non-commercial.

\section{INTRODUCTION}

The evolvement of information technology (IT) has currently envisaged many devices linking to the internet that uninterruptedly produce data around the physical setting using the internet of things (IoT). IoT has instigated to development of the prevalence of connectivity presenting an innovative era of a network. This innovation model, a smooth object, or a thing, is well-found with drive-in sensors and web connectivity together to works as a principal structure block that expedite communication, interaction, and incorporation with the physical environment around us to deliver intelligence services that 
are useful and accomplish collective objectives (Yan et al., 2014) The mechanism adopted by the internet of things could be like a fridge-freezer that trails the expiration of food and fruits and independently forwards a request notice to food and fruits outlets. Also, it may be an air cleaner in the living room that instructs occupants about dampness levels, al fresco pollution, an indicator light, which changes color at detection of an impostor, or any insolent objects well- regulated by and linked to the internet, which is capable of generating and segment data over the system (Kopetz, 2011).

Additionally, to implement the designated purposes, the gadgets may cooperate and interact with individual devices. For instance, exploiting the integrated sensors to create the internet of things oriented to survey and assist in preventing domestic issues, or embedding the generated information to manage the lighting, warmth at the fire place, adjust power depletion, air conditioning system and other automated appliances all through the house. From a theoretical point of view, the autonomous, hitherto thoroughly interlocked, nature of thought-provoking questions concerning the psychological coordination of data sources. The conventional Sender-Message-Channel-Receiver (SMCR) ideology of message transmission proposes that the origin of the channel of communication and message which is conveyed to the recipient is the sender (Kim, 2016).

There are so many auspicious solutions that have been proposed to handle the heterogeneity and the complexity of the internet of things objects. The most conspicuous methods are to improve computer-generated settings to resolve the thought- provoking questions initiated by the heterogeneous things. Virtualization is gradually becoming a crucial component in the internet of things structural design, in the system of one or the other virtual objects or entities. It backs allotment of data collected by the individuals and the gadgets orientated on the social interactions. These connections further stimulate well-organized innovation of the objects and operational service structures (Ali et al., 2018). Nevertheless, this sequence of communication turns out to be somewhat intricate in human- internet of things communication for the reason that the internet of thing is a system including diverse objects transferring data to the recipient conceptually things can be alleged as high-tech bases somewhat than ordinary channels of messaging -particularly as they show anthropomorphic interfaces and characteristics (Vadlamudi, 2015). If such a designation of origin is feasible, at that time would each gadget transfer its activity, or would all gadgets convey a sole activity? Even at that, what are the impacts of distinct against multiple basis designation in the internet of things? In such a form of interconnected system where several purposes are shared between the entire group of objects (Borgia, 2014), can the objects be seen having adequate technical know-how in the data which they convey? Sketching made on the computers are known as social actors, design agency, modality, navigability, and interconnectivity design of machinery impacts. However, this article is aimed to explore interrelating socially with the internet of things and the influence of source attribution and its specialization between human.

\section{LITERATURE REVIEW}

This section focuses on the review of related literature in connectivity, attribution and specialization in human- IoT interaction. Internet of Things as Hi-tech Source Vadlamudi (2015) in their clarification of online causes, argued that the source is a psychological and subjective, instead of an unreserved and complete, theory that is designed by what the receiver relies on the source to be. However, computers, search engines optimization, televisions, interface characteristics could be consider as a source of data or as a technical origin, despite ontologically, they are not an independent source (Movva et al., 2012). 
This represents the actual concept particularly when the transferred mechanism are such as anthropomorphic signalas gender, voice, interactivity, expertise, and personality as a result of CASA model suggestions, human communications with computers are basic social, and their computer- facilitated understanding is handled relatively altogether as non-facilitated and real-life understanding (Vadlamudi, 2016). According to Langer, 1989, he viewed the ontological channel of communication such as the computer begins as a psychosomatic source of info, and as a result, the channel impacts develop as persuasive, if not more, as the communication impacts perceived in the customary communication paper (Addington, 1971).

Based on the theory. A sequence of CASA work has revealed that the human-computer interface should certainly track the social procedures of the human-human interface. In other words, people spontaneously use social directive and well-educated social performances in their interfaces with those computers that show anthropomorphic signals, even if they are cognizant that they are interrelating within living mediators (Ahmed et al., 2020). For instance, researchers have verified that people assign better credibility to generalist computer (Vadlamudi, 2021), accept more to computers that prompt state of mind of happiness and anger (deMelo et al., 2011), and reply more absolutely to computers with a voice revealing a disposition comparable to their own (Nass et al., 1999). The social signal is usually related to easy recovery and distinctively human, categories, social schemas, and stereotypes (Lakshmi Narayana et al., 2012). People seem to be impulsively respond to these kind of signals when evaluating the value of such interface along with the data developed by using its short of vigorously giving out all pertinent appropriate characteristics of the condition (Nass \& Moon, 2000).

However, human replies to machine incline to be used not as social objects but as monotonous, which happens because of decreased devotion instigated by the major depen dence on the formerly reputable social principles and groupings (Langer, 1989). Unbiasedly as humanhuman communication is mainly and asininely directed by a less number of important signals that describe the condition, the anthropomorphic signal in computers robotically stimulate robust social replies and tip the people to overlook the detail that computers are not frank human players. The current innovation in communication and information technology (ICT) has qualified the application of numerous smart, interface properties and assembly of the internet-allowed gadgets that are fortified with innovative ability liking to one of the straight computers (Hayes, 2013). This recommends that internet of things gadgets all together have the prospect to be seen as hi-tech sources, instead of simple interaction media, particularly when trying to attempt to interact with operators or consumers in a social mode using their shrewd, anthropomorphic properties (Cohen et al., 2004). Source attribution voice as an origin signal spreading the CASA model to this work, internet of things gadgets that interact using their unique voices can be seen more definitely than the one that distributes an undistinguishable voice, fairly as data conveyed from multiple talkers and supporters is usually estimated as more trustworthy (Macho \& Ledermann, 2011).

This is as a result of two distinct factors namely:

- The Voice factor which is a robust source signal that produces strong social replies.

- An artificial voice equals a source. Hence, duplicating voices signify the reality of multiple sources (Vadlamudi, 2020).

A clarification for the multiple voices impact from the data handling collected works is that anthropomorphic signal like voice, suggest the social existence experiential, or the impression that technologically savvy consumers do not be acquainted with the synthetic of such non- 
human social players and communicate with the skill as though with a social object or a smart object instead with a non-living object (Biocca, 1997, Donepudi at al., 2020a).

Anytime such an experiment is activated, it helps as a noticeable, marginal psychological shortcut that mostly defines the expiration and worth of the vital content (Rahman et al., 2020). In elucidating the contribution by the numerous signals that exist in technology, Donepudi et al., (2020b) assumes the MAIN paradigm and classified modality in elucidating the role played by the various cues present in technology, Donepudi et al., (2020b) opined that MAIN an acronyms which means; (M), activity (A), interactivity (I), and navigability $(\mathrm{N})$, are 4 kinds of technology perceived signal that an object may be used to implement a precise action that is unanimously existing deepest digital media. These are perceived signals that an object may be used to implement a precise action are demonstrated in the arrangement of surface-level topographies and noticeable crossing points that signal cognitive heuristics proceeding to feign valuations of facilitated content. More explicitly, Donepudi et al., (2020b) debates that once an innivation displays the activity of a perceived signal that an object may be used to implement a precise action through anthropomorphic structures, a social existence heuristic is activated to evaluate the content and nature of the communication. For instance, scholars (Kim et al., 2013; Lee et al., 2015) exploited corresponding behaviors, social roles, humanlike presence, and independence to allot activity signals to computers. They originate that the incidence of such signals prompted such a robust social existence, which, in chance, ensued in more optimistic assessments of the computers about their cleverness, dependability, social fascination, and security. Thus, people thoughtlessly depend on the triggered heuristic to create snap decisions of given data (usually in an optimistic direction) deprived of likable systematic charges of the content (Donepudi et al., 2020b; Kim \& Sundar, 2016). Source Specialization: Single Capability as a Strong suit Signal Proficiency implies the precision, reliability, dependability, capability, and requirement of a source (Ohanian, 1990; Donepudi et al., 2020b; Vadlamudi, 2021).

In the territory of human-computer interface, CASA investigations have steadily verified that information coming from a proficient computer ranked as more reliable, dependable, and advanced in feature than that offered by a proletarian or a general practitioner computer (Donepudi et al., 2020b; Koh \& Sundar, 2010; Vadlamudi, 2021), which is steady with results in the human-human interface. Proficiency encourages operators to establish optimistic estimates of and insolences to the content of the info and the machinery that brings it. This suggests that internet of things tools would, as industrial bases of info, display adequate proficiency to provoke inordinate social replies and upsurge the trustworthiness and excellence of the info they convey (Rindskopf, 1984). After that being mentioned, what are the possible approaches for introducing higher proficiency in the gadgets? Frankly speaking one of the ways of introducing proficiency or know-how in the internet of things tools or gadgets is to specialize them in a way that the function is simple (Harkins \& Petty, 1981).

However, you may agree with us that people usually show or have specialty to equipment with simplify or few functions such as the weather station, ignite e-book reader, etc. than the one with so many functions as applicable in human-human communication whereby they had to depend more on human brain specialty (Koh \& Sundar, 2010; Vadlamudi, 2021).

Providentially, the area of concentration can be executed simply by classification or imprinting. For instance, Nass et al. (1996) opened participants to identify entertainment and news video excerpts on TV sets considered "Entertainment TV", "News TV" (i.e., dedicated), or "Entertainment/News TV and bring into being such contents expected through the dedicated Televisions were ranked much more definitely otherthan the one 
with the same contents expected from a general TV (Koh \& Sundar, 2010). Likewise, Vadlamudi (2021) revealed that specifying a smart gadgets to accentuate its one primary role (e.g., smartphone, Galaxy "Note") steered operators to rely on that smartphone designed for a particular function instead of general-purpose, tool specialized to a specific expanse of the domain that in turn, persuaded more trust in the gadgets (Leshner et al., 1998; Macho \& Ledermann, 2011). These results propose that people have a tendency to answer to dedicated computers just as they would do to human experts and those domain that could be allotted by accentuating its functionality of tools through classification- assists as a basis signal that qualities activity to the tools (Donepudi et al., 2020b). The MAIN prototypical viewpoint, such a signal would activate the know-how experientially, or the notion that info approaching from specialists can be reliable, which tips operators to the snap finding that the origin is dependable and trustworthy (Chaiken, 1987; Vadlamudi, 2021).

As mentioned previously, the MAIN prototypical suggests that the performance of activity signals induces variations in operator opinions by activating heuristics that facilitate technology operators' findings of the feature and reliability of the fundamental content (Donepudi et al., 2020b). Interface Effects of Source Specialization and Source Attribution Here, when we are referring to the interface effect of source specialization and source attribution, it is a way of conveying the 2 social signals that are specialty and voice to produce the views of more than one source and proficiency, this work examines the likelihood that internet of things tools are seen as hi-tech sources.

These signal does not occur in segregation, instead, they exist in both improve level sources to hi-tech and direct people to reply socially to the internet of things tools as autonomy sources of info. Assumed that internally pertinent causes can co-occur in the series of information exchanges (Vadlamudi, 2015), the intelligence of activity persuaded by more than one source provenance and source specialization may potent interaction impacts on the way people interrelate with the internet of thing gadgets (Sundar et al., 2007).

\section{MeTHOD}

The method described by Kim (2016) was adopted for this study to explore cooperating on a social basis with the IoT: impacts of source specialization and attribution in human- IoT interface. Four conditions signifying different levels of source attribution that is single source against multiple sources and to kinds of gadget functionality that is single against multiple was studied at George Mason University, United State of America. A total of eighty participants take part in this study consisting (40 males and 40 females undergraduate students) who agreed to participate in the student were analyzed. Respondents' ages range from 17-25 years.

\section{Hypothesis for the study}

Two hypotheses were used for the study, namely;

- Receiving info from more than one sources, instead of a single source, will give rise to the higher existence of IoT gadgets

- Receiving info from single-function internet of things gadgets, instead of multifunction gadgets, give rise to a higher sense of the know-how of the gadgets. 


\section{Device and Inducement Message}

A controlled laboratory was selected for this experiment, just like a normal living room. 3 identical speakers with a rechargeable battery, a television, table, home theatre device, and sofa, and wireless connectivity to a smartphone, computer, and tablet. The speakers used in this study were linked to the internet, which serves as a personal vocal sound sub. The speakers function remotely sent acoustic files selected by the experimenter. Three classes of information were selected from news websites with neutral content that covers traffic, local weather, and events. These sets of information were converted to audio files via text-tospeech software. Archives were arbitrarily allotted to one out of 3 internets of things (IoT) gadgets and remotely played. The volume information in each of the archives was identical.

\section{Investigational Management Situation}

\section{Operation of source Designation or Attribution}

According to Vadlamudi (2020) states that more than one artificial vocal sound was set up to persuade an intelligence of the existence of more than one speaker. Thus, the degree of source designation was operated by creating an atmosphere for the participants to fluctuating numbers of artificial voices conveying information. In more than one source situation, each of the 3 internets of things gadget conversed with participants using their vocal sound. These vocal sounds did not resemble each other, on the other hand, they were automated in a manner that each one signified the male and sent the communication in an unbiased, intonation means. In disparity, all 3 IoT apparatus in one source condition conveyed the message utilizing the same vocal sound.

\section{Operation of specialization source}

The degree of specialization was manipulated as several utilities the internet of things gadgets provided one against three. The degree of IoT gadgets functionality was pasted beneath the gadget. In the case of a sole-utility equipment situation, the following description was read by participants: "This gadget function at the lowest hi-speed quad-core portable Intel CPU with connectivity and high RAM rating. It offers modified data on climate or occasions or road traffic in the environs according to the data generated from the network and by its set in devices." In disparity, respondents for the multifunction toolset read, "This gadget functions ... data on the climate or occasions or road traffic in the environs according to the data generated from the network and by its set in devices." This operation aimed to provide the ringing that the apparatus was technically able of treating either multiple or single utilities and that the center of their actions was the running of one and three types of information too.

\section{The process involved in the experiment}

Participant consented to the experiment and was assigned operation conditions according to their time of arrival. Instructions about the study were given to them before the commencement of the experiment. One of the instructions in the investigation was an opportunity for them to interact with internet of things gadgets mounted in the computerizegenerated portable lab and the extent of user interface with the gadgets through the investigation period. Respondents were instructed to freely move all over the place and study the different functionality degrees as each of the participants move close to the internet of things gadgets. Having accomplished this task, the IoT gadget starts sending messages beginning with greetings in either single or multiple vocal sounds. The messages were directed using a computer that is wirelessly connected to the internet of things gadgets through a wireless connection like Bluetooth. Having interacted with all the gadgets, 
respondents were instructed to go ahead with the online questionnaire that produced their assessments of the dignified variables designated below. The whole investigation process was carried out on an individual level to all the respondents for the duration of 1200 seconds.

\section{Measures}

The respondents answered each item in the questionnaire by specifying according to the scale. All items in the questionnaire were revised from authenticated investigations and a slight modification to help us achieve the objective of this study. Positive element scrutiny was conducted on the generated information using the upper limit probability guess procedure which established the cogency of the investigated element setting (fit indices: $\chi 2 / \mathrm{df}=1.41, \mathrm{CFI}=0.94, \mathrm{IFI}=0.94$, RMSEA $=0.06,95 \%$ CI [0.06-0.08], p<0.001).

Social existence ( $\alpha=0.80$ ) were dignified with the aid of an index collected of 5 items revised according to Lee et al. (2006) investigation: "It points to as if I was networking with a smart creature," "It points out as if I was complemented by a smart creature," "It points out as if I was unaccompanied in the room" (overturned), "It sensed as if the gadgets were responding to me," and "It points out as if the gadgets and I was interacting."

Apparent know-how of the IoT policies $(\alpha=0.72)$ was dignified with the aid of 5 suitable items revised from Ohanian's (1990) study. The items involved "skilled," "amateur" (retreated), "fit," "expert," and "erudite. "These items were put together to assess the level to which respondents sensed that the internet of things expedients had adequate proficiency in the area of the info the gadgets conveyed.

Insolence in the direction of the internet of things strategies $(\alpha=0.68)$ was determined with the aid of 5 items revised from Kim and Sundar's (2014) investigation. Respondents specified how intensely they decided with all the succeeding reports:

- Is utilizing these gadgets is an upright idea?

- Or it is having a regularly promising approach concerning these gadgets?

- Do you like the concept of using these gadgets?

- Is the use of this gadget valuable?

- Do these gadgets make your life further fascinating?

The general value of conveyed data $(\alpha=0.72)$ was determined according to Sundar's (2000) approach which broadcast the discernment scale. Respondents designated to what degree they sensed the set of information was "believable," "flawless," "precise," "factual," "complete," "fair," "important," "objective" and "educational." Dispute participation ( $\alpha$ $=0.65$ ) was studied with the aid of 5 items revised from Zaichkowsky (1985) investigated. Respondents designated the level at which the data given was "significant," "applicable," "useful," "of no use to them" and "required."

\section{RESULTS AND DISCUSSION}

Operation Check

The participants were instructed to answer the following items on the questionnaire on the weighted scale of 7 ;

- It manipulated as if numerous objects were interacting with them.

- It manipulated as if the participant was in the same room with multiple objects 
- These gadgets were multi-functional

- Each of these devices had a detailed utility

Self-determining section t-tests established noteworthy variation in the assessments of attribution of the source, $\mathrm{t}(78)=8.85, \mathrm{p}<0.001$, and specialization, $\mathrm{t}(78)=12.28, \mathrm{p}<0.001$. The contributors were more in the offing to distinguish that they were networking with more than one objects when the info was conveyed by more than one vocal sound (Mean $=5.60$, Standard Deviation $=0.85$ ), as parallel to a single voice (Mean $=3.86$, Standard Deviation $=0.80$ ). Additionally, contributors perceived the variation between multifunction (Mean $=1.93$, standard deviation $=0.70)$ and single-function $(\mathrm{M}=3.54$, Standard Deviation $=.79)$ gadgets.

\section{Hypothesis Assessments}

\section{Impacts of source specialization and multiple source attribution}

The collected data were subjected to a two-way analysis of variance (ANOVA) to determine the impacts of source specialization and attribution on the dignified variable (see Table 1 ). The participants who communicated with the internet of things devices producing multiple sources practiced more social existence, $\mathrm{F}(1,96)+20.79$, $\mathrm{p}<0.001$, np $2=0.19$, showing multiple affirmative attitudes towards the gadgets, $\mathrm{F}(1,96)=20.15, \mathrm{p}<.001, \eta \mathrm{p} 2=0.17$, and assessed the communicated info greater in worth, $\mathrm{F}(1,96)=16.24, \mathrm{p}<0.001, \eta \mathrm{p} 2=0.15$, than did those who interrelated with an on its source. Consequently, hypothesis (H1) was reinforced. The outcomes of the ANOVA shown that participants who expected info from the single-function devices credited more know-how, $\mathrm{F}(1,96)=17.61, \mathrm{p}<.001, \eta \mathrm{p} 2=0.16$, exhibited more affirmative insolences concerning the strategies, $\mathrm{F}(1,96)=26.56, \mathrm{p}<.001, \eta \mathrm{p} 2=0.22$, and assessed the communicated info higher in worth, $\mathrm{F}(1,96)=16.77, \mathrm{p}<.001, \eta \mathrm{p} 2=0.15$, than those who networked with the multifunction devices. Thus, hypothesis 4 (H2) was also maintained.

Table 1: A two-way analysis of variance (ANOVA) to determine the impacts of source specialization and attribution

\begin{tabular}{|c|c|c|c|c|c|c|}
\hline \multirow{3}{*}{$\begin{array}{c}\text { Measured } \\
\text { variable }\end{array}$} & \multicolumn{6}{|c|}{ Mean } \\
\hline & \multicolumn{3}{|c|}{ Source Attribution } & \multicolumn{3}{|c|}{ Source Specialization } \\
\hline & $\begin{array}{l}\text { Multiple } \\
\text { source }\end{array}$ & $\begin{array}{l}\text { Single } \\
\text { source }\end{array}$ & $\mathrm{F}$ & $\begin{array}{c}\text { Multiple } \\
\text { functionality }\end{array}$ & $\begin{array}{c}\text { Single } \\
\text { functionality }\end{array}$ & $\mathrm{F}$ \\
\hline $\begin{array}{c}\text { Social } \\
\text { Existence }\end{array}$ & $6.26(0.14)$ & $4.85(0.14)$ & $54.55 * *$ & $5.15(0.14)$ & $5.95(0.14)$ & $17.61 * *$ \\
\hline $\begin{array}{l}\text { Perceived } \\
\text { Know-how }\end{array}$ & $6.23(0.14)$ & $5.32(0.14)$ & $20.79 * *$ & $5.58(0.14)$ & $5.98(0.14)$ & $4.12 *$ \\
\hline Insolence & $5.33(0.13)$ & $4.47(0.13)$ & $20.15 * *$ & $4.40(0.13)$ & $5.40(0.13)$ & $26.56 * *$ \\
\hline Info quality & $5.16(0.09)$ & $4.67(0.09)$ & $16.24 * *$ & $4.66(0.08)$ & $5.17(0.08)$ & $16.77 * *$ \\
\hline
\end{tabular}

$* \mathrm{p}<.05, * * \mathrm{p}<.001$

\section{Interaction between source specialization and source attribution}

Concerning the questionnaire, double interfaces between source specialization and source attribution estimate insolence, $\mathrm{F}(1,96)=20.15, \mathrm{p}<0.001, \eta \mathrm{p} 2=0.17$, and info quality, $\mathrm{F}(1$, $96)=16.24, \mathrm{p}<.001, \eta \mathrm{p} 2=.15$, were originate 17 to be important. The outcomes of the ANOVA proposed that the single-function gadgets persuaded more optimistic insolences (Figure 1) and greater info worth (Figure 2) than the multiple functionality devices when the info was conveyed from a source. Such variances were not perceived when the info was communicated by multiple sources. 


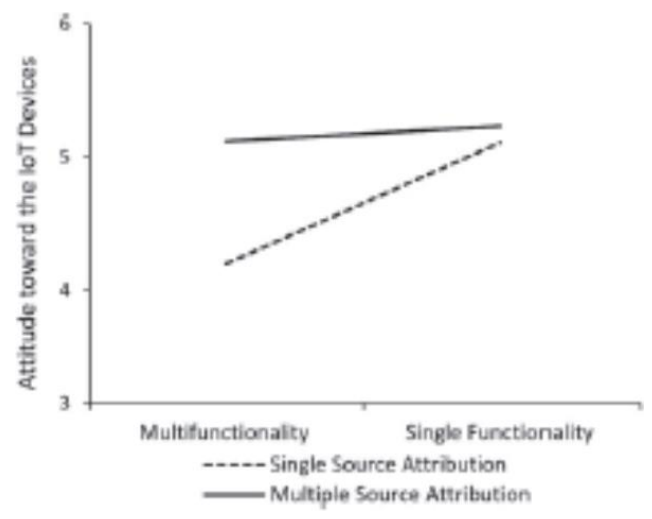

Figure 1: The outcome of the ANOVA showing the interaction of source attribution and Specialization estimating the insolence towards the Internet of things

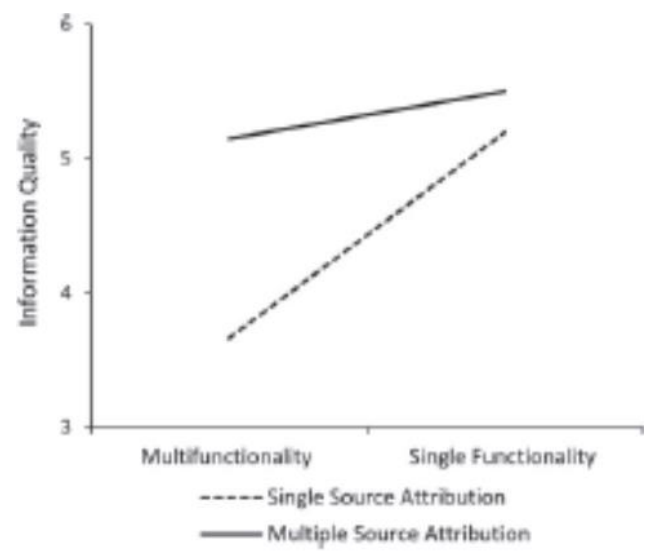

Figure 2: The outcome of the ANOVA showing the interaction of source attribution and Specialization estimating the info quality

\section{Effect of sources - single and multiple}

The effect of the source to interacting socially with IoT is presented below (Figure 3) based on the percentage of selection from the participants.

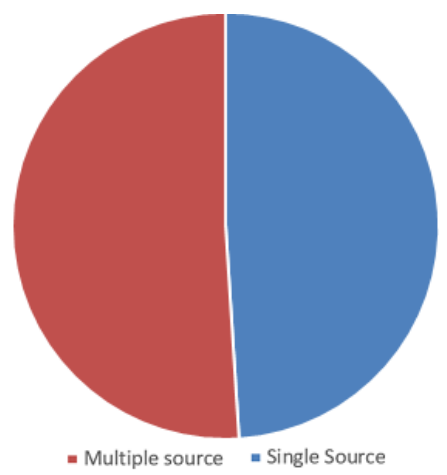

Figure 3: Chart showing the effect of IoT information sources. 


\section{Discussion}

This research embraces psychological and operators' experience as a method to understand better the human-internet of things communication, and shows that extend of source attribution and specialization affects how operators recognize IoT gadgets and data obtained from them. The major role of this work is the interpretation of the contribution of multiple sources in inducing human-internet of things communications and the addition of the pertinent collected works to the domain of ubiquitous networks flawlessly interwoven by smart entities. Tentatively, the multiple sources affect witnessed in this research not only allows the reinvasion of the SMCR model by demonstrating that objects can be apparent as hitech sources instead of simple media of interaction but also ratifies the manipulation of the CASA model and its applicability to the setting of socially feeling human-IoT communication. Being reliable with the CASA debated that people asininely obey social rules when interacting with computers, participants in this research might have consigned uniqueness to the artificial voices of the IoT profile just as they would have done with dependable human voices, and consequently ranked their communication with the many sources more definitely than they would have assessed by their interface with only one source.

The outcome that multiple source attribution improves the quality of info only for lowinvolvement people supports further probes the multiple source effect. This result is reliable with entrenched dual-process models of data processing (Rahman et al., 2020; Chaiken, 1987) signifying that low-involvement personalities are more accessible to heuristic signals and less disposed to systematic rates of communicated content. The results also expose that the impacts of multiple source attribution are more distinct for personalities for whom the content of the data has low special relevance.

\section{CONCLUSION}

The IoT is bringing a new pace by connecting to so many devices on the planet and allowing intelligent internet of things facilities. This study concludes that multiple source attribution improves the quality of data in interacting socially with IoT and also addresses the effects of specialization in human-internet of a thing interaction. However, this study recommend improvement of attribution source and human specialization-IoT.

\section{REFERENCE}

Addington, D.W. (1971).The effect of vocal variations on ratings of source credibility. Speech Monographs, 38, 242-247.

Ahmed, A. A. A., Donepudi, P. K., \& Asadullah, A. B. M. (2020). Artificial Intelligence in Clinical Genomics and Healthcare. European Journal of Molecular \& Clinical Medicine, 7(11), 1194-1202, https:/ / ejmcm.com/? action=article\&au=24014

Biocca, F. (1997).The cyborg's dilemma: Progressive embodiment in virtual environments. Journal of Computer-Mediated Communication, 3(2).

Borgia, E. (2014).The Internet of things vision: Key features, applications, and open issues. Computer Communications, 54, 1-31.

Chaiken, S. (1987). The heuristic model of persuasion. In M. Zanna, J. Olson, \& C Herman (Eds.), Social influence:The Ontario symposium (Vol. 5, pp. 143-177). Hillsdale, NJ: Erlbaum.

Cohen, M. H., Giangola, J. P., \& Balogh, J. (2004). Voice user interface design. Redwood City, CA: Addison-Wesley.

Donepudi, P. K., Ahmed, A. A. A., Hossain, M. A., \& Maria, P. (2020a). Perceptions of RAIA 
Introduction by Employees on Employability and Work Satisfaction in the Modern Agriculture Sector. International Journal of Modern Agriculture, 9(4), 486-497. https://doi.org/10.5281/zenodo.4428205

Donepudi, P. K., Ahmed, A. A. A., Saha, S. (2020b). Emerging Market Economy (EME) and Artificial Intelligence (AI): Consequences for the Future of Jobs. Palarch's Journal of Archaeology of Egypt/Egyptology, 17(6), $5562-5574$. https://archives.palarch.nl/index.php/jae/article/view/1829

Harkins, S. G. \& Petty, R. E. (1981).The effects of source magnification of cognitive effort on attitudes: An information processing view. Journal of Personality and Social Psychology, 40, 401-413.

Hayes, A. F. (2013). Introduction to mediation, moderation, and conditional process analysis. NewYork: Guilford Press.

Kim, K. J., \& Sundar, S. S. (2014). Does screen size matter for smartphones? Utilitarian and hedonic effects of screen size on smartphone adoption. Cyberpsychology, Behavior, and Social Networking, 17(7), 466-473.

Kim, K. J., Park, E., \& Sundar, S. S. (2013). Caregiving role in human-robot interaction: A study of the mediating effects of perceived benefit and social presence. Computers in Human Behavior, 29(4), 1799-1806.

Kim, K.J. (2016). Interacting Socially with the Internet of Things (IoT): Effects of Source Attribution and Specialization in Human-IoT Interaction. Journal of Computer-Mediated Communication, pp. 1-16.

Koh, Y. J., \& Sundar, S. S. (2010). Heuristic versus systematic processing of specialist versus generalist sources in online media. Human Communication Research, 36(2), 103-124.

Kopetz, H. (2011). Real-time systems: Design principles for distributed embedded applications. NewYork: Springer.

Lakshmi Narayana S., Suneetha Devi J., Bhargav Reddy I., Harish Paruchuri. (2012). Optimizing Voice Recognition using Various Techniques. CiiT International Journal of Digital Signal Processing, 4(4), $135-141$

Langer, E. L. (1989).Minding matters: The consequences of mindlessness-mindfulness. In L. Berkowitz (Ed.), Advances in experimental psychology, vol. 22 (pp. 137-173). San Diego, CA: Academic Press.

Lee, J., Kim, K. J., Lee, S., \& Shin, D. (2015). Can autonomous vehicles be safe and trustworthy? Effects of appearance and autonomy of unmanned driving systems. International Journal of HumanComputer Interaction, 31(10), 682-691.

Lee, K. M., Peng,W., Jin, S, \& Yan, C. (2006). Can robots manifest personality? An empirical test of personality recognition, social responses, and social presence in human-robot interaction. Journal of Communication, 56(4), 754-772.

Leshner, G., Reeves, B., \& Nass, C. (1998). Switching channels: The effects of television channels on the mental representations of television news. Journal of Broadcasting \& Electronic Media, 42(1), 2133.

Macho, S., \& Ledermann, T. (2011). Estimating, testing, and comparing specific effects in structural equation models: The phantom model approach. Psychological Methods, 16(1), 34-43.

Movva, L., Kurra, C., Koteswara Rao, G., Battula, R. B., Sridhar, M., \& Harish, P. (2012). Underwater Acoustic Sensor Networks: A Survey on MAC and Routing Protocols. International Journal of Computer Technology and Applications, 3(3).

Nass, C., \& Moon, Y. (2000). Machines and mindlessness: Social responses to computers. Journal of Social Issues, 56(1), 81-103.

Nass, C., Moon, Y., \& Carney, P. (1999). Are respondents polite to computers? Social desirability and direct responses to computers. Journal of Applied Social Psychology 29(5), 1093-1110. 
Nass, C., Reeves, B., \& Leshner, G. (1996). Technology and roles: A tale of two TVs. Journal of Communication, 46(2), 121-128.

Ohanian, R. (1990). Construction and validation of a scale to measure celebrity endorsers' perceived expertise, trustworthiness, and attractiveness. Journal of Advertising, 19(3), 39-52.

Rahman, M. M., Chowdhury, M. R. H. K., Islam, M. A., Tohfa, M. U., Kader, M. A. L., Ahmed, A. A. A., \& Donepudi, P. K. (2020). Relationship between Socio-Demographic Characteristics and Job Satisfaction: Evidence from Private Bank Employees. American Journal of Trade and Policy, 7(2), 6572. https://doi.org/10.18034/aitp.v7i2.492

Rindskopf, D. (1984). Using phantom and imaginary latent variables to parameterize constraints in linear structural models. Psychometrika, 49(1), 37-47.

Sundar, S. S. (2000). Multimedia effects on processing and perception of online news: A study of picture, audio, and video downloads. Journalism \& Mass Communication Quarterly, 77(3), 480499.

Sundar, S. S., Knobloch-Westerwick, S., \& Hastall, M. R. (2007). News cues: Information scent and cognitive heuristics. Journal of the American Society for Information Science and Technology, 58(3), 366-378.

Vadlamudi, S. (2015). Enabling Trustworthiness in Artificial Intelligence - A Detailed Discussion. Engineering International, 3(2), 105-114. https://doi.org/10.18034/ei.v3i2.519

Vadlamudi, S. (2016). What Impact does Internet of Things have on Project Management in Project based Firms?. Asian Business Review, 6(3), 179-186. https://doi.org/10.18034/abr.v6i3.520

Vadlamudi, S. (2020). Internet of Things (IoT) in Agriculture: The Idea of Making the Fields Talk. Engineering International, 8(2), 87-100. https://doi.org/10.18034/ei.v8i2.522

Vadlamudi, S. (2021). The Economics of Internet of Things: An Information Market System. Asian Business Review, 11(1), 35-40. https://doi.org/10.18034/abr.v11i1.523

Yan, Z., Zhang, P., \& Vasilakos, A. V. (2014). A survey on trust management for Internet of Things. Journal of Network and Computer Applications, 42, 120-134.

Zaichkowsky, J. L. (1985). Measuring the involvement construct. Journal of Consumer Research, 12(3), 341-352.

\section{How to Cite:}

Vadlamudi, S., \& Hargrove, D. L. (2021). The Internet of Things (IoT) and Social Interaction: Influence of Source Attribution and Human Specialization. Engineering International, 9(1), 29-40. https://doi.org/10.18034/ei.v9i1.526 